\title{
A 12-Year-Old Girl with Bilateral Coats Disease and ABCA4 Gene Mutation
}

\author{
Ali Osman Saatci ${ }^{a}$ Ziya Ayhan ${ }^{a}$ Aylin Yaman ${ }^{a} \quad$ Elcin Bora ${ }^{b}$ \\ Ayfer Ulgenalp $^{\mathrm{b}}$ Salih Kavukcu ${ }^{\mathrm{c}}$ \\ ${ }^{a}$ Department of Ophthalmology, Dokuz Eylul University, Izmir, Turkey; ${ }^{b}$ Department of

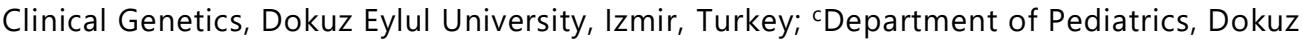 \\ Eylul University, Izmir, Turkey
}

\section{Keywords}

ABCA4 gene $\cdot$ Coats disease $\cdot$ Dexamethasone implant (Ozurdex)

\begin{abstract}
A 12-year-old girl with bilateral stage 2B Coats disease was screened meticulously for a possible underlying systemic disease as she was female and the disease was bilateral. Full systemic workout turned out to be unremarkable. However, an ABCA4 gene mutation was found in the genetic analysis. NDP and TINF2 gene mutations were not present. She was successfully treated with a bilateral, single intravitreal injection of dexamethasone implant and a single session of indirect laser photocoagulation with a relatively good anatomic and functional result. To the best of our knowledge, the present case is the only reported case of Coats disease with an ABCA4 gene mutation.

(C) 2018 The Author(s) Published by S. Karger AG, Basel
\end{abstract}

\section{Introduction}

Coats disease is an idiopathic retinal telangiectasia characterized by dilated, small-to-medium-sized blood vessels with an irregular caliber and with intraretinal and/or subretinal exudation without significant retinal or vitreal traction [1-3]. The disease is unilateral in $95 \%$ of cases with male predilection in $76 \%$ of cases. However, ultra-widefield imaging modalities have shown that male patients with unilateral Coats disease also had retinal pathology, mostly 
at the temporal retinal quadrant, in their clinically unaffected fellow eyes [4]. Less common genetically determined isolated or syndromic ocular conditions can present with Coats-like posterior segment changes such as dyskeratosis congenita, facioscapulohumeral dystrophy, Turner syndrome, incontinentia pigmenti, Kabuki syndrome, Norrie disease, Retinitis pigmentosa with Coats-like retinopathy, Senior-Loken syndrome, and Revesz syndrome $[5,6]$.

We hereby present a 12-year-old girl with bilateral Coats disease and ABCA4 gene mutation who was successfully treated with a bilateral, single dexamethasone implant (Ozurdex) and a single session of indirect laser photocoagulation.

\section{Case Report}

A 12-year-old girl was referred to us with bilateral gradual visual deterioration in July 2013. Her past medical and family histories were normal. On our examination, her best-corrected visual acuity (BCVA) was 3/10 in OD and 2/10 in OS. Slit-lamp examination was unremarkable OU. Applanation tonometer was $15 \mathrm{~mm} \mathrm{Hg}$ bilaterally. Fundus examination demonstrated almost symmetrical bilateral marked intraretinal and subretinal exudation, telengiectatic vessels, and macroaneurysms localized to equatorial fundus and temporal fundus OU. Fluorescein angiography revealed bilateral significant capillary nonperfusion noted mostly in the temporal retinal periphery together with light-bulb-like capillary dilations and staining of telangiectatic vessels (Fig. 1a, b). Optical coherence tomography disclosed bilateral intraretinal cystic edema more severe in the left macula (Fig. 1c, d). There were also hyperreflective dots in the posterior vitreous of the right eyeball due to mild intravitreal hemorrhage. The clinical appearance was compatible with bilateral stage 2B Coats disease according to the classification [7]. However, as the patient was female and bilateral involvement was present, she was hospitalized to obtain a full systemic workout [8]. A thorough systemic examination and laboratory evaluation including cranial and total body imaging were carried out. The only positive finding was the presence of vitiligo patches throughout her body and extremities. All treatment options were discussed with the family and we decided to treat her with combined bilateral laser photocoagulation and dexamethasone implant (Ozurdex) administration according to our previous positive experience [9-11]. Under general anesthesia, bilateral indirect laser scatter photocoagulation was administered over all peripheral nonperfused retinal areas. After completion of the photocoagulation, the bilateral intravitreal dexamethasone implant (Ozurdex) injection was performed (Fig. 2a, b). The intraretinal/subretinal exudation and foveal intraretinal edema resolved gradually with time. Three years after the initial presentation, she underwent uneventful consecutive phacoemulsification surgery followed by intraocular lens implantation a month later. Her BCVA was 4/10 in OD and 3/10 in OS at the last visit performed in February 2018. Both fundus appearances were quiescent with some evidence of epiretinal membrane formation OU (Fig. 3a-d). A meticulous genetic workout was carried out during the follow-up, and an ABCA4 mutation was revealed. The genetic analysis is summarized below.

\section{Genetic Analysis: Pathogenic}

The genetic analysis was started with Sanger sequencing for the NDP gene and no pathogenic variant was found.

Exome sequencing (IIlumina HiSeq 2500 platform) revealed compound heterozygous variations of the $\mathrm{ABCA} 4$ gene: p.458L (c. $1373 \mathrm{C}>\mathrm{T}$ ) variation was located in the 11th exon and was reported as pathogeneic in HGMD (CM970016) and ClinVar (ID: 7888) databases; 
p.G1961E (c.5885 G>A) variation was found in the 42nd exon and was not reported as pathogeneic in public databases (ExAc, EVS, dbSNP, 1000GP). In contrast, silicon analysis tools predicted it was pathogeneic. The final result was variable of uncertain significance for p.G1961E. The mutations found were in concordance with Stargardt disease 1 (OMIM \#248200). According to the same exome sequencing analysis there was no TINF2 gene mutation.

\section{Discussion}

In the workup of patients with Coats disease, it is important to differentiate between isolated disease and syndromic disease with Coats-like retina changes. The present case had two less common clinical features: bilaterality of the disease and female gender. Thereby, we decided to carry out a meticulous systemic workout including full neuroimaging and genetic analysis. Though the clinical assessment was inconclusive, genetic analysis pointed out an ABCA4 mutation. Black et al. [12] suggested that Coats telengiectasia could be secondary to somatic mutation in the NDP gene, which might result in a deficiency of norrin within the developing retina. However, no mutation in the NDP gene could be identified in the present case. The ABCA4 (also known ABCR) gene on the short arm of chromosome 1 has been implicated in Stargardt disease and fundus flavimaculatus [13]. ABCA4 codes for a member of the ATP binding cassette transmembrane protein located in the rim of the photoreceptor disks and is involved in the transport of all-trans retinol through the disk membrane. ABCA4 protein dysfunction causes accumulation of all-trans retinol in the photoreceptors and in the retinal pigment epithelium. All-trans retinol is then converted to N-retinylidane-N-retiniylethanolamine which is toxic to retinal pigment epithelium and photoreceptors [14]. We reviewed the literature to look for the association between ABCA4 gene mutation and Coats-like disease spectrum. More than 40 years ago, Deutman [15] reported a female patient (age not given) with bilateral atrophic maculopathy attributed to Stargardt disease and unilateral Coats disease treated with photocoagulation. No detailed clinical information was given. Also, no genetic testing could be performed at that time.

The association of several systemic diseases with Coats disease should be kept in mind, especially in cases with atypical features such as the present case. The revealed ABCA4 mutation in our 12-year-old female patient with bilateral Coats disease could be a mere coincidence as the carrier frequency in the general population of ABCA4 alleles is about 5-10\% [16]. To the best of our knowledge, this is the only case of Coats disease with an ABCA4 gene mutation reported thus far and our intention was to share our observation with the ophthalmic community.

\section{Statement of Ethics}

The subject of this case report provided informed consent under family supervision for the publication.

\section{Disclosure Statement}

The authors have no financial or proprietary interest in the material presented herein. 


\section{References}

1 Shields JA, Shields CL, Honavar SG, Demirci H. Clinical variations and complications of Coats disease in 150 cases: the 2000 Sanford Gifford Memorial Lecture. Am J Ophthalmol. 2001 May;131(5):561-71.

2 Shields JA, Shields CL. Review: coats disease: the 2001 LuEsther T. Mertz lecture. Retina. 2002 Feb;22(1): 80-91.

3 Sigler EJ, Randolph JC, Calzada JI, Wilson MW, Haik BG. Current management of Coats disease. Surv Ophthalmol. 2014 Jan-Feb;59(1):30-46.

4 Rabiolo A, Marchese A, Sacconi R, Cicinelli MV, Grosso A, Querques L et al. Refining Coats' disease by ultrawidefield imaging and optical coherence tomography angiography. Graefes Arch Clin Exp Ophthalmol. 2017 Oct;255(10):1881-90.

5 Reichstein DA, Recchia FM. Coats disease and exudative retinopathy. Int Ophthalmol Clin. 2011;51(1):93112.

6 Tekin NF, Saatci AO, Kavukçu S. Vascular tortuosity and Coats'-like retinal changes in facioscapulohumeral muscular dystrophy. Ophthalmic Surg Lasers. 2000 Jan-Feb;31(1):82-3.

7 Shields JA, Shields CL, Honavar SG, Demirci H, Cater J. Classification and management of Coats disease: the 2000 Proctor Lecture. Am J Ophthalmol. 2001 May;131(5):572-83.

8 Kivelä T. George coats and his disease. Ophthalmologica. 2012;228(3):194-5.

9 Saatci AO, Doruk HC, Yaman A. Intravitreal dexamethasone implant (ozurdex) in coats' disease. Case Rep Ophthalmol. 2013 Sep;4(3):122-8.

10 Parlak M, Saatci AO. A review of intravitreal treatment alternatives used as an adjunctive therapy in Coats' disease. Int J Ophthalmic Res. 2015;1(3):71-6.

11 Ayhan Z, Unlu B, Parlak M, Yaman A, Berk AT, Ozer E et al. Coats hastalığı ve tedavisi. Ret Vit. 2017;26:301.

12 Black GC, Perveen R, Bonshek R, Cahill M, Clayton-Smith J, Lloyd IC et al. Coats' disease of the retina (unilateral retinal telangiectasis) caused by somatic mutation in the NDP gene: a role for norrin in retinal angiogenesis. Hum Mol Genet. 1999 Oct;8(11):2031-5.

13 Allikmets R. Simple and complex ABCR: genetic predisposition to retinal disease. Am J Hum Genet. 2000 Oct;67(4):793-9.

14 Koenekoop RK. The gene for Stargardt disease, ABCA4, is a major retinal gene: a mini-review. Ophthalmic Genet. 2003 Jun;24(2):75-80.

15 Deutman AF. Unexpected findings in hereditary macular dystrophy. Doc Ophthalmol Proc Ser. 1975;7:281312.

16 Yatsenko AN, Shroyer NF, Lewis RA, Lupski JR. Late-onset Stargardt disease is associated with missense mutations that map outside known functional regions of ABCR (ABCA4). Hum Genet. 2001 Apr;108(4):34655. 


\section{Case Reports in Ophthalmology}
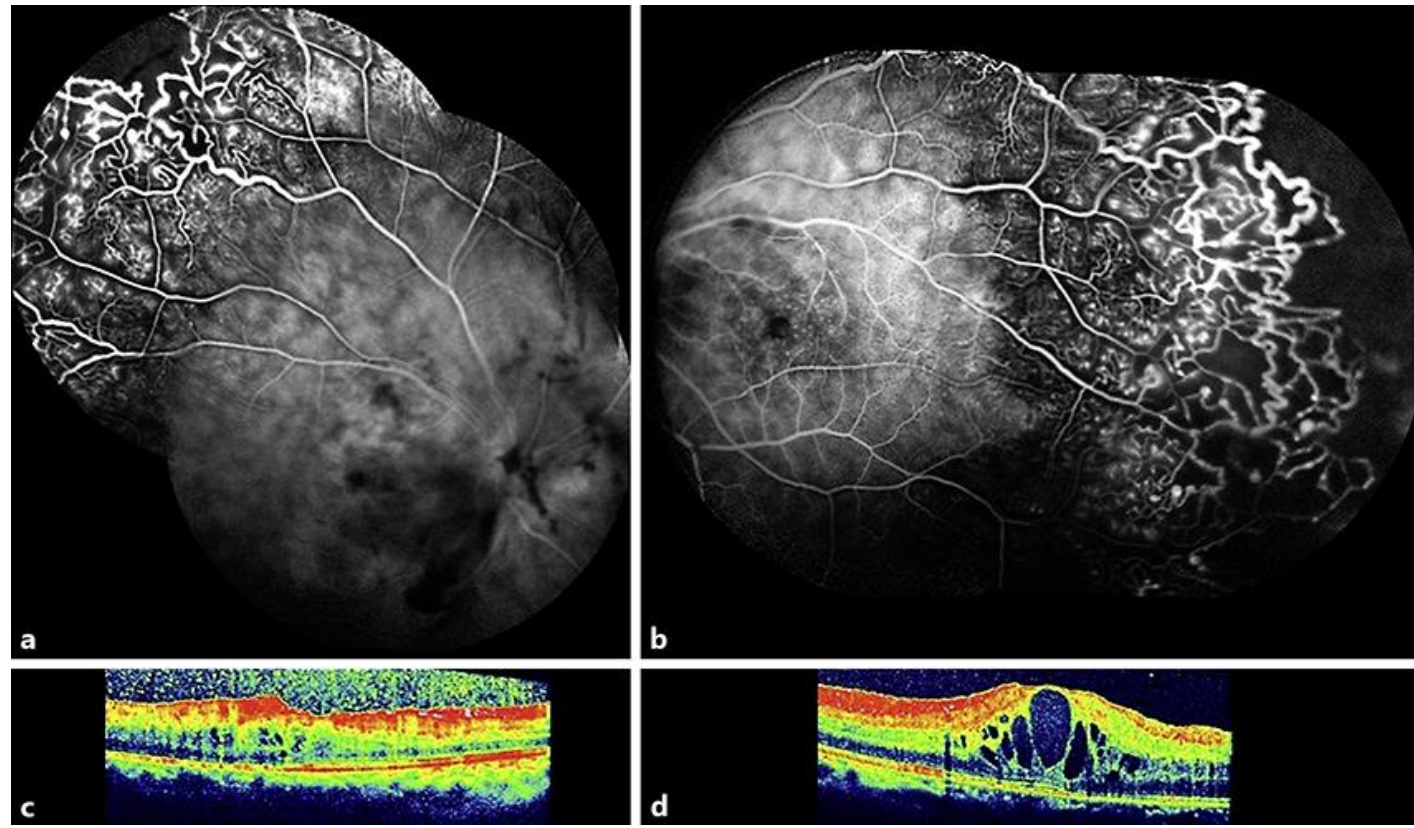

Fig. 1. Composite fluorescein angiographic images of the right (a) and left (b) eyes showing the macular hyperfluorescence related to edema, staining of the telengiectatic vessels, peripheral capillary nonperfusion areas, and light-bulb-like capillary enlargements. Optical coherence tomography depicting the intraretinal cystoid changes in the right (c) and left (d) maculae together with hyperreflective dots in the posterior vitreous of the right eye corresponding to the mild hemorrhage.
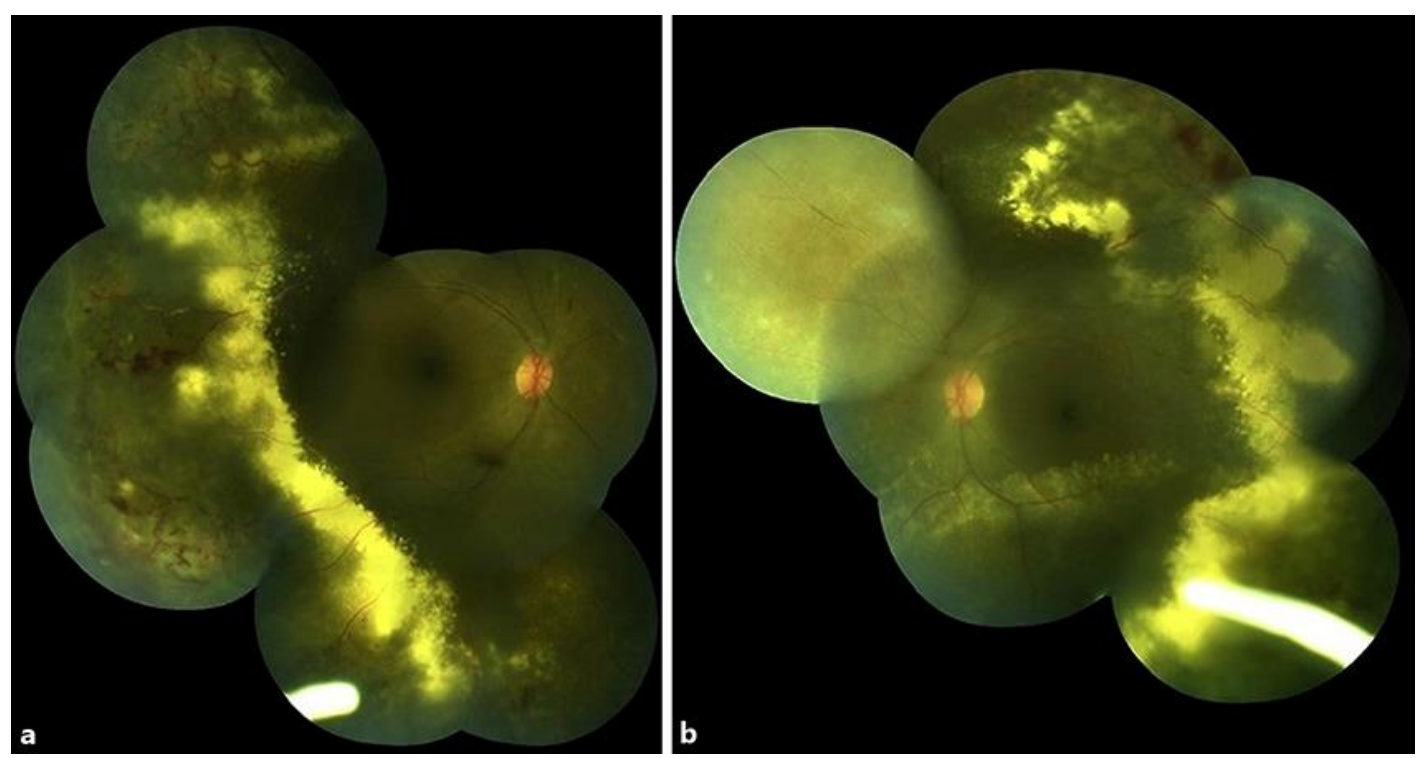

Fig. 2. Composite color fundus images of the right (a) and left (b) eyes taken 8 days after the bilateral indirect laser photocoagulation and dexamethasone implant injection showing the faint scattered photocoagulation scars and the dexamethasone implant. 


\section{Case Reports in Ophthalmology}
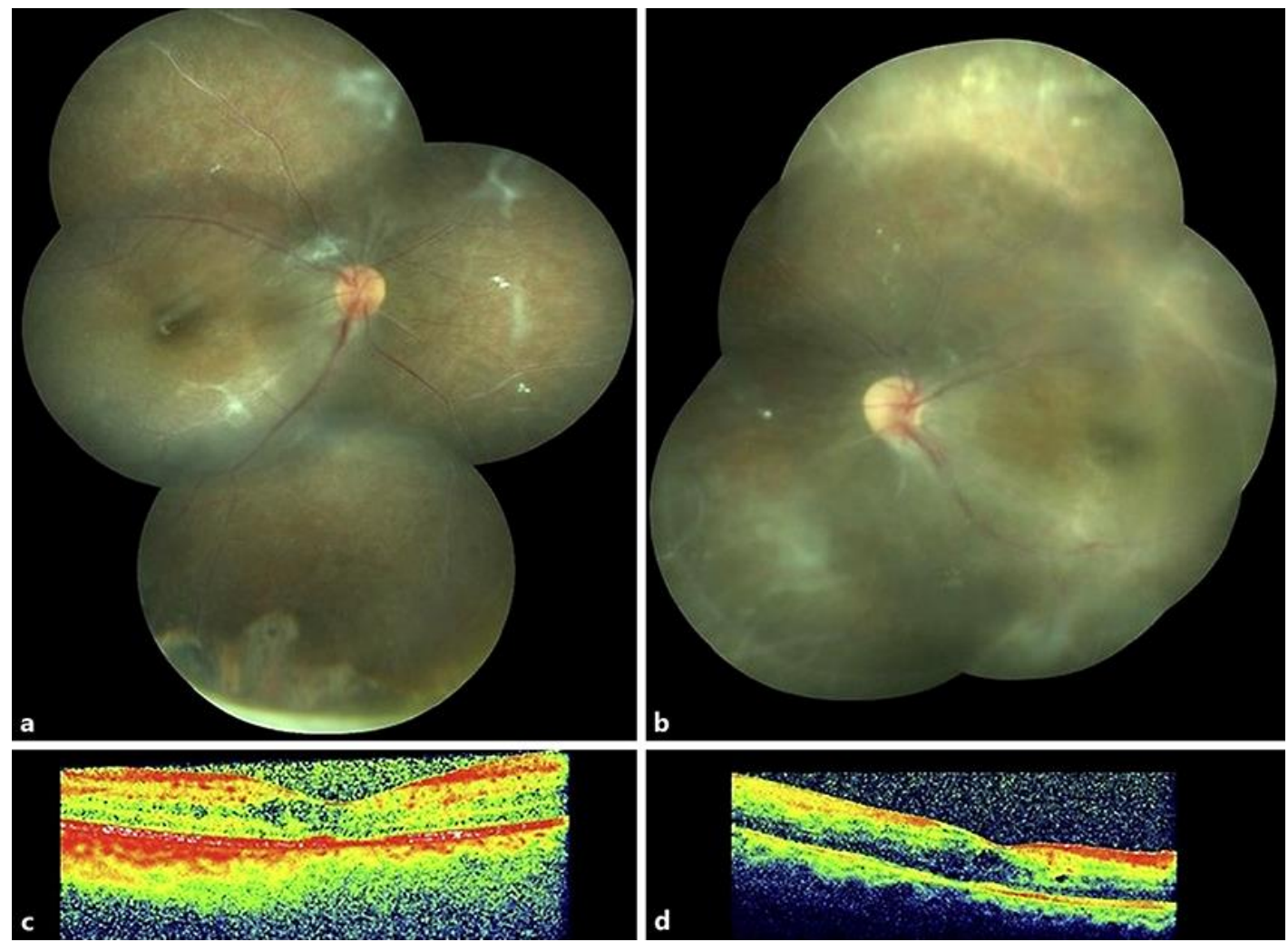

Fig. 3. Composite color fundus images of the right (a) and left (b) eyes showing the quiet posterior poles with some signs of epiretinal membrane formation. The left optic nerve head was slightly dragged temporally. Optical coherence tomographic images of the right (c) and left (d) maculae depicting the relatively normal foveal architecture. 